\title{
The Influence of E-Learning towards Metacognitive Enhancement in Mathematical Problem Solving
}

\author{
https://doi.org/10.3991/ijet.v14i20.11466 \\ Nurul Shida $\left({ }^{\varpi}\right)$, Sharifah, Hanifah, Norulhuda, Abdul Halim \\ Universiti Teknologi Malaysia, Kuala Lumpur, Malaysia \\ nurul ashida@yahoo.com
}

\begin{abstract}
This research aims to observe the influence of e-learning on metacognitive enhancement in mathematical problem-solving. The e-learning environment would encourage students to play more active roles in their learning. This research involves the students of Mechanical Engineering Department enrolled in the subject of Engineering Mathematics 4. It was found that the elearning method gives positive impacts on students' learning process. Therefore, it is suggested for educators to apply this method in their teaching. This is a suitable approach for students to be involved actively during their learning process. The lecturers should be more creative and innovative to vary their elearning to be lively, interesting, suitable, challenging while being in line with the students' cognitive development to provide comprehensible input.
\end{abstract}

Keywords-Metacognitive, e-learning, problem solving, polytechnic, mathematics.

\section{$1 \quad$ Introduction}

Recently, electronic learning is gaining more attention of educational institutions after its efficiency in helping students to be involved actively in learning has been observed. Nevertheless, several higher educational institutions are utilizing e-learning as an alternative for students who are having problems in attending face-to-face classes. Introducing e-learning is a brilliant step to give the teachers more options in the teaching and learning process. It can overcome the problems caused by conventional teaching method, attract students' interest and also encourage students to be more competitive and confident. The interactive design, information and presentation in web-portal sites motivates students to explore the wide and interesting world of learning, especially the scientific world that is full of wonders. Furthermore, it can bring the students out from their classroom to explore the real scientific world.

In e-learning, the main principle is student-centered. Students make planning and find information with their own ability and effort. The interesting elements in elearning and students' interest towards the functions in the internet has lead to a wide usage of e-learning for teaching and learning. The success of national e-learning agenda depends on the application of ICT in higher educational institutions. In line with the recent development of computer and multimedia technology, the teaching 
process has undergone positive changes in which the lecturers' teaching method has been improved and strengthened with the use of multimedia. Therefore, this study carried out the influence of e-learning towards metacognitive enhancement in mathematical problem solving. The reason is, students consider Mathematics as a boring field of knowledge and sometimes, they memorize the method without understanding the steps taken. This has sparked an idea to the researcher that students' metacognitive in mathematical problem solving can be enhanced by utilizing e-learning. Furthermore, it will give a brief understanding on students' metacognitive enhancement after they have experienced e-learning. The metacognitive ability is enough potential to improve the meaningfulness of students' learning mathematics in classroom (Bahri \& Heryaningsih, 2018). It is thinking of a thinking process that involves higher order of thinking. Metacognitive skills requires an understanding of metacognition within the problem-solving process (Jagals \& Van Der Walt, 2016). Metacognitive awareness, belief and attitude towards the problem solving are variables, which affect the problem solving process significantly (Sağirli, 2016). It includes an individual's awareness on thinking, exploring various problem solving method, involving in intellectual learning experience through self-motivation and curiosity driven by emotion, instinct, mind, spiritual and personality to produce an existent concrete. The operation involves planning, observing and evaluating strategies on thinking skill, strategies and other cognitive processes. Metacognitive students were better of perceiving the characteristics of constructivist learning environment (Kirbulut \& Gokalp, 2014). This gives an added value in the teaching process. The three main objectives for this research are to study whether e-learning can enhance metacognitive in mathematical problem solving., to identify if there is a significant difference in the achievement of marks for pretest and post-test of mathematics between traditional learning and e-learning and $t o$ study whether e-learning can help enhance students' achievement in mathematical problem solving.

Metacognitive-based scheme had a positive impact on students' understanding of the problem posed, solution planning, confidence in and personal control of problemsolving behavior and emotions (Lee, Yeo, \& Hong, 2014). Deep cognitive and metacognitive strategies would result in higher levels of problem solving achievement (Muis, Psaradellis, Lajoie, Di Leo, \& Chevrier, 2015). Metacognitive is a mental process that should be developed together with other cognitive processes to produce reflective students. Students should learn, discuss and apply it consistently. Thinking is a process that uses mind whether to gain meaning or understanding towards something, make consideration and decisions or solve problems.

Metacognitive is an important aspect in determining the success or failure in problem solving (Bergstra, 2015). However, many researches stated that students were less exposed to it and were weak in metacognitive skill. Students' metacognition characteristic that are measured are metacognitive knowledge, which is students' knowledge on cognitive strategy for mathematical problem solving and regulation towards related cognition with planning, observation and evaluation. Metacognitive has been acknowledge as an intelligence; those who can organize their own thought are considered more intelligent. It has become an important concept in researches because many evidences had shown that this skill can be learned and is able to enhance students' 
performance. student is demonstrating metacognitive skills, by describing what it is he learned, as well as how he believes he learned it (Alwine, 2014).

Many researchers believed that metacognitive can improve students' achievement and this is connected to a positive academic outcome such as an increase in grade and performance. The understanding towards metacognitive process can be seen through the influence of metacognitive activity towards the outcome of students' problemsolving process. Problem solving is a major component in Mathematics. The problem solving activities are important because the ability to process, organize and use information in the context of problem solving is a need in today's society. Metacognitive has been identified as the key to mathematical problem-solving process. Researches on the role of metacognitive in Mathematics activities especially in problem solving are connected to two components related to the knowledge on an individual's thinking process and observation of activities during the problem-solving process. The success in problem solving is depending more on existing knowledge such as concept knowledge in long-term memory only.

\section{Methodology}

This section discusses the research method used to study the influence of e-leaning towards metacognitive enhancement in mathematical problem solving. This research involves semester 5 students from Polytechnic Ibrahim Sultan. The samples chosen were the students of Mechanical Engineering Department enrolled in the subject Engineering Mathematics 4. Two classes were selected and divided into two groups. The first one is the control group who received traditional teaching and learning method, while the second one is the experimental group who received e-learning learning approach. The students in both groups have almost the same and balanced capability.

The research instrument was a set of questions which was used during pre-test which before e-learning and traditional teaching and learning method were used. The pre-test and post-test comprise five questions involving problem solving questions and given to both groups. The same set of questions was used as the post-test for the control group after they had received the traditional teaching method 'chalk and talk' and the experimental group after they had used e-learning which applies metacognitive characteristics. Data analysis and processing for both pre-test and post-test were made using descriptive analysis method using the SPSS software Most of the styles are intuitive. However, we invite you to read carefully the brief description below.

\section{$3 \quad$ Findings}

In this study, the experimental group used e-learning as one of the teaching and learning approach. A total of 30 students were selected to use it because the computer lab only provided 33 units of computer. This will give the students the chance to use the computer personally, with one person using one computer. The data gained from the result was analyzed to study the influence of e-leaning towards students' meta- 
cognitive enhancement in solving mathematical problems after the research was carried out for both experimental group and control group.

It was found that the respondents from the control group comprises 24 males (80\%) and 6 females (20\%). Meanwhile, the experimental group comprises 29 males $(96.7 \%)$ and 1 female $(3.3 \%)$.

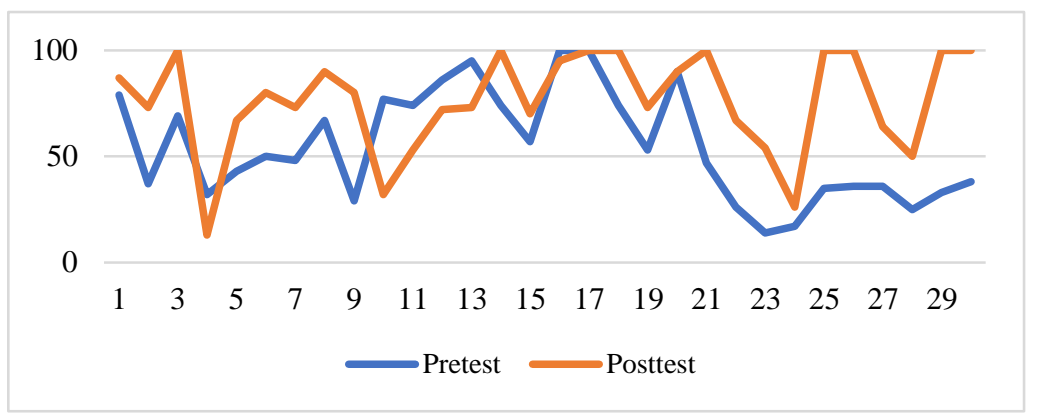

Fig. 1. Line Graph of Student Performance in Control Group for Pre-test and Post-test

Fig. 1 shows the students achievements in a line graph. The graph analysis shows the students' improvement in the achievement of post-test as compared to pre-test. For the control group, 14 students (47\%) achieved weak level, 8 students $(27 \%)$ had average level, while 4 students $(13 \%)$ achieved good level. Meanwhile, for the experimental group, 3 students $(10 \%)$ had weak achievement, 12 students $(40 \%)$ achieved average level, while 15 students (50\%) achieved good level. The gap between the lined of pre-test and post-test represents the differences between the post-test and pretest.

Fig. 2 illustrates the students' performance in a line graph. The graph analysis shows the students' improvement in the achievement of post-test as compared to pretest. The gap between the lined of pre-test and post-test represents the differences between the post-test and pre-test.

Before the traditional teaching method was given to control group and e-learning was applied to experimental group, a pre-test had been carried out. The test scores were analyzed using the SPSS software. The mean for pre-experimental groups showed higher result than that of pre-treatment group which is 59.0, compared to 54.70. The mean difference was 4.3.

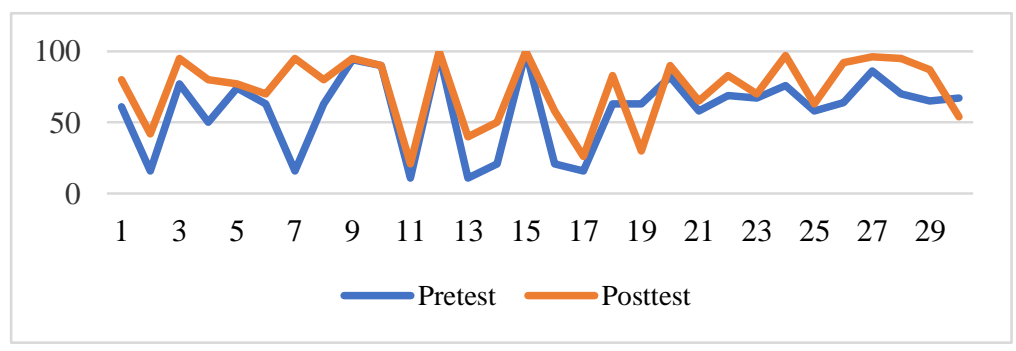


Fig. 2. Line Graph of Student Performance in Experimental Group for Pre-test and Post-test

Table 1. Scores Analysis for Post-test

\begin{tabular}{|l|c|c|c|}
\hline \multicolumn{1}{|c|}{ Group } & n & Mean & SD \\
\hline Control & 30 & 76.07 & 23.909 \\
\hline Experiment & 30 & 73.47 & 23.562 \\
\hline
\end{tabular}

After traditional teaching method was used to control group and e-learning was applied to experimental group, a post-test was carried out. The test scores were analyzed by using the SPSS software. The mean for post-control test was 76.07 which is higher than that of post-experimental group which was 73.47. The mean difference was 2.6.

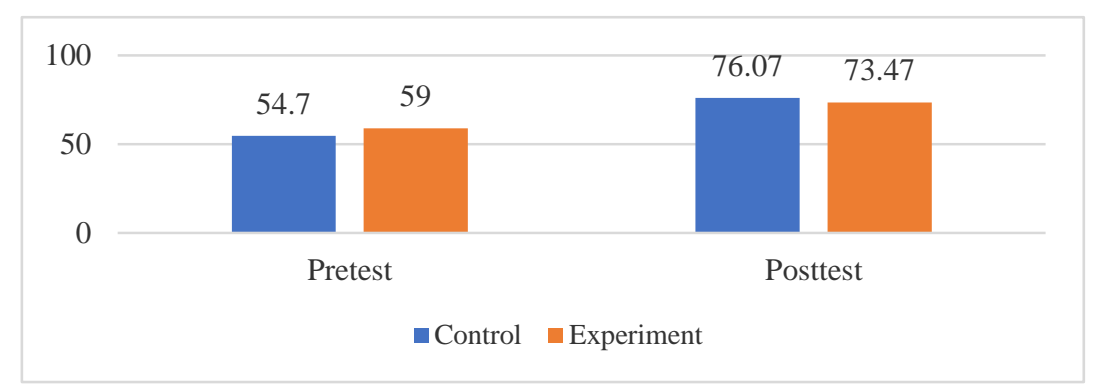

Fig. 3. Comparison of Min Score Between Experiment and Control Group

The bar graph provides the comparison of mean score between experimental group and control group. The mean score for pre-test of experimental group shows a high mean value which is 59, whereas the control group recorded a mean of 54.7. Meanwhile, the post-test of experimental group shows a mean of 73.47, while the control group displayed a mean of 76.07 .

Table 2. Paired Samples Correlations for Pre-test and Post-test for Control and Experimental Group

\begin{tabular}{|l|c|c|c|}
\hline & N & Correlation & Sig. \\
\hline PreControl \& PostControl & 30 & .337 & .069 \\
\hline PreExperiment \& PosExsperiment & 30 & .731 & .000 \\
\hline
\end{tabular}

There is a strong correlation in the experimental group where they did their best during the pre-test and post-test with $\mathrm{p}<0.05$. However, the opposite applies to the control group.

Table 3. t-Test Analysis for Post-test

\begin{tabular}{|l|c|c|c|}
\hline & Min t & Df & Sig (2 tailed) \\
\hline Post-test & 26.924 & 29 & 0.000 \\
\hline
\end{tabular}


Table 3 present the t-Test analysis for post-test. There is a significant difference between the control group and the experimental group in the post-test for $\mathrm{p}<0.05$.

Table 4. Paired Samples t-test Comparing Mean Score Pre-test and Post-test for Experimental Group

\begin{tabular}{|c|c|c|c|c|c|}
\hline Mean & SD & 95\% CI & t & df & Sig. \\
\hline-14.467 & 18.811 & {$[-21.491,-7.443]$} & -4.212 & 29 & .000 \\
\hline
\end{tabular}

Table 4 shows a t-test to test the difference of mean score variables of pre-test and post-test for experimental group. It is found that the $t$ value is -4.212 , with a signifant value (2-tailed) of 0.000 . Hence, there is a significant difference between the mean scores of pre-test and post-test of experimental group after the students were exposed to e-learning.

Table 5. Paired Samples t-test Comparing Mean Score in Pre-test and Post-test for Control Group

\begin{tabular}{|c|c|c|c|c|c|}
\hline Mean & SD & $\mathbf{9 5 \%}$ CI & t & df & Sig. \\
\hline-21.367 & 28.493 & {$[-32.006,-10.727]$} & -4.107 & 29 & .000 \\
\hline
\end{tabular}

Table 5 shows the t-test to test the difference of the mean score variable of pre-test and post-test for the control group. It was found that the $t$ value is -4.107 , with a significant value (2-tailed) of 0.000 . There is a significant difference between the mean scores of pre-test and post-test for the control group after the students were exposed to traditional method. Therefore, based on this result, it is shown that the mean scores for the pre-test and post-test of the control group after being exposed to traditional teaching and learning has a significant difference.

Table 6. Paired Samples t-Test Mean Score in Pre-test for Experimental Group

\begin{tabular}{|c|c|c|c|c|c|}
\hline Mean & SD & $\mathbf{9 5 \%}$ CI & t & df & Sig. \\
\hline-4.300 & 42.562 & {$[-20.193,11.593]$} & -.553 & 29 & .584 \\
\hline
\end{tabular}

Table 6 shows a t-test to test the differences of mean score variable of the pre-test for both control group and experimental group. It was found that the $t$ value is -.553 and the significant value (2-tailed) was 0.584 . There was no significant difference between the mean scores of pre-test for the control group and the experimental group. Therefore, this result shows that there was no significant difference between the mean scores of pre-test for both control group and experimental group.

Table 7. Paired Samples t-Test Mean Score in Post-test for Experimental Group

\begin{tabular}{|c|c|c|c|c|c|c|}
\hline Mean & SD & \multicolumn{2}{|c|}{ 95\% CI } & t & df & Sig. \\
\hline 2.600 & 36.445 & -11.009 & 16.209 & .391 & 29 & .699 \\
\hline
\end{tabular}


Table 7 shows the t-test to test the difference of mean scores variable of post-test for the control group and the experimental group. It was found that the $t$ value was 0.391 and the significant value (2-tailed) gained was 0.699 . There was no significant difference between the mean scores of post-test for the control group and the experimental group. This result shows that the difference between the mean scores of posttest for the control group and experimental group was not significant.

\section{Conclusion}

Based on the results of the analysis for the pre-test and post-test, it has clearly portrayed a significant improvement in terms of students' achievement as a whole. The score average gained from the pre-test was 59\%, while for the post-test, the score average was $73.47 \%$. This means that the marks increase was $14.47 \%$. A traditional teaching method was used in the pre-test. Most students achieved weak achievement which were 14 students, while 8 students achieved average level and 4 students achieved good level. After the e-learning session was carried out, the test score had increased. 17 students achieved good level, 8 students achieved average level, and 5 students achieved weak level. From the scores of the post-test, it is proven that the use of e-learning learning method does help in enhancing students' performance. The analysis shows that the use of e-learning which uses various volours and interesting graphics in the teaching and learning process is very effective.

The research implication shows that the students used controlled strategies a lot. The skill of using metacognitive strategy requires guidance from educators. Several strategies and steps to solve problems shall be taught and shown before the learning activity occurs. It is also found that students apply evaluating strategy a lot by questioning themselves before, during and after answering questions. Metacognition can be developed by providing opportunities for students to do reflection and categorizing their actions based on two or more evaluating criteria. For example: identifying and differentiating an action whether it helps or hinders to identify what is liked and disliked by listing down the pros and cons of an activity.

Educators should encourage students to record or illustrate an experience in a logbook while they are undergoing the experience. This can help students to synthesize or translate their thoughts and behaviours through symbols or graphics, to look back on their original perception and comparing the original perception with the new decision, to process their thought on the strategy and the decision making identifying weakness in the action made and reminiscing the success or difficulties in a trial. Finally, to tackle the students' weakness during the phase of observing and evaluating, the researcher has proposed an activity that can be carried out by the educators in the Mathematics class to enhance the two phases by student. Teachers or educators can use the activity proposed according to the suitability of the class and the students' capability. Based on the research, it was found that the e-learning method gives positive impacts towards students' learning process. Therefore, it is suggested for educators to apply this method in their teaching.This is a suitable approach for students to be involved actively during their learning process. The lecturers should be 
more creative and innovative to vary their e-learning to be lively, interesting, suitable, challenging while being in line with the students' cognitive development to provide comprehensible input. Thus, this research would help our country to create a more effective e-learning system for the society and higher institutions in Malaysia in the future. Furthermore, the suggestions proposed in this research can help education executives in Malaysia to identify the aspects needed to create a more effective learning using e-learning.

\section{$5 \quad$ References}

[1] Alwine, S. (2014). A Case Study Examining The Explicit Method of Critical Thinking Instruction in a Community College English Classroom.

[2] Bahri, A., \& Heryaningsih, N. Y. (2018). Description of Student' s Metacognitive Ability in Understanding and Solving Mathematics Problem Description of Student 's Metacognitive Ability Understanding and Solving Mathematics Problem. https://doi.org/ $10.1088 / 1757-899 \times / 300 / 1 / 012048$

[3] Bergstra, A. S. (2015). Towards effective learning strategies. University of Groningen. Retrieved from https://www.rug.nl/research/portal/files/20100976/Complete_thesis.pdf

[4] Jagals, D., \& Van Der Walt, M. (2016). Enabling metacognitive skills for mathematics problem solving: A collective case study of metacognitive reflection and awareness. African Journal of Research in Mathematics, Science and Technology Education, 20(2), 154 164. https://doi.org/10.1080/18117295.2016.1192239

[5] Kirbulut, Z. D., \& Gokalp, M. S. (2014). The Relationship Between Pre-Service Elementary School Teachers 'Metacognitive Science Learning Orientations and Their Use of Constructivist Learning Environment, 22(6), 1-10. https://doi.org/10.1080/09720073.20 13.11891346

[6] Lee, N. H., Yeo, D. J. S., \& Hong, S. E. (2014). A metacognitive-based instruction for Primary Four students to approach non-routine mathematical word problems. ZDM - International Journal on Mathematics Education, 46(3), 465-480. https://doi.org/10.1007/s $\underline{11858-014-0599-6}$

[7] Muis, K. R., Psaradellis, C., Lajoie, S. P., Di Leo, I., \& Chevrier, M. (2015). The role of epistemic emotions in mathematics problem solving. Contemporary Educational Psychology, 42, 172-185. https://doi.org/10.1016/j.cedpsych.2015.06.003

[8] Sadeghi, B., Hassani, M. T., \& Rahmatkhah, M. (2014). The Relationship between EFL Learners ' Metacognitive Strategies, and Their Critical Thinking, 5(5), 1167-1175. https:// doi.org/10.4304/jltr.5.5.1167-1175

[9] Sağirli, M. Ö. (2016). the Metacognitive Awarenesses of Pre- Service Secondary School Mathematics Teachers, Beliefs, Attitudes on Problem Solving, and Relationship Between Them 1, 12(2), 464-482.

\section{Authors}

Nurul Shida is a Phd student at University Technology Malaysia. (nurul ashida@ya hoo.com)

Sharifah is a senior lecturer at University Technology Malaysia. (sharifah.o@utm.m y) 
Hanifah is a senior lecturer at University Technology Malaysia. (hanifah-j@utm.m у)

Norulhuda is a senior lecturer at University Technology Malaysia. (p-norulhuda@ut m.my)

Abdul Halim is an Associate Professor at University Technology Malaysia. (p-hali m@utm.my)

Article submitted 2019-08-17. Resubmitted 2019-09-23. Final acceptance 2019-09-27. Final version published as submitted by the authors. 